\title{
A Comparison of False-Information Policies in Five Countries before and during the COVID-19 Pandemic
}

\author{
Xiaohua Zhu ${ }^{1}$ \\ University of Tennessee, Knoxville \\ xzhu12@utk.edu
}

\author{
Shengnan Yang ${ }^{1}$ \\ Indiana University, Bloomington \\ yang290@iu.edu
}

\author{
Summer Allen \\ University of Tennessee, Knoxville \\ $\underline{\text { sallen54@vols.utk.edu }}$
}

\begin{abstract}
This study analyzes five countries' falseinformation policies before and during the COVID-19 pandemic. Building upon existing discussions of regulation models, this paper uses a qualitative, comparative case study method to unpack the characteristics of false-information policies in each country. The before-after comparisons show that each country has a unique evolving path of falseinformation regulation and that the state has enhanced or attempted to enhance its role in battling against the infodemic during the pandemic. The regulatory practices are a dynamic process and involve not only government and social media platforms but also multiple other actors, which is leading to more complex practices and blurring the boundary of existing models. We discuss the limitation of existing regulation models and suggest a relational perspective to understand the underlying relations between the state, platforms, and other stakeholders.
\end{abstract}

\section{Introduction}

While COVID-19 spreads all over the globe, the world also experiences an upsurge of different kinds of false information - fake news, rumors, myths, misinformation, disinformation, conspiracy theories, and even hatred - disseminated on social media platforms. As United Nations Secretary-General António Guterres said in a video message, a "global 'misinfo-demic' is spreading," which travels faster than the virus itself [1]. While some international nongovernmental organizations, including the United Nations and the World Health Organization, are leading the battle against this infodemic, virtually all national governments are also addressing the problem directly (e.g., publishing "mythbusters") or indirectly (e.g., providing accurate information). This study is a comparative study of false-information policies before and during the pandemic in five national governments - Argentina, China, France, the US, and the UK. We use the phrase "false information" as an umbrella term for misinformation, fake news, disinformation, and rumors, in order to emphasize the inaccuracy of content and embrace the variety of behavioral intentions and spread channels $[2,3]$.

This paper presents the preliminary findings and results of a larger and more theoretical research project on international misinformation policies. We try to answer the following research questions: What information policies (including laws, policies, regulations, orders, and government announcements) have these governments issued or updated during the COVID-19 pandemic? How do they differ from the pre-COVID policies? How do they differ among the countries? Answers to these questions come through an in-depth content analysis of both government websites and other information/news outlets to gain a better understanding of the impact of the global pandemic on misinformation-related policies. This preliminary analysis also enables theoretical discussions of broader information policy issues.

\section{Literature Review}

The COVID-19 pandemic has exacerbated the problem of false information online. Some studies have looked at the nature of COVID-19 related false information and policy reactions from the perspective of journalism [4] or government law-making [5-7]. These studies, however, only scratch the surface and invite further policy research.

There does exist a considerable body of preCOVID false-information policy literature, which tends to focus on the regulation models and the underlying relations between two main actors, governments and social media platforms [8-12]. Several authors have proposed different models to theorize policy responses to inaccurate online information $[5,9,10,13]$. While they may differ slightly in terminology, these models are highly comparable. They operate along a spectrum of increasing governmental control, from little or no oversight to intense regulation which reflects different kinds of relation between government and platform.

At one end of the spectrum is regulation that focuses on the social media platforms themselves with limited, if any, governmental oversight. It is known as self-governance, self-regulation, and even non-audited

\footnotetext{
${ }^{1}$ These authors contributed equally to this work.
} 
self-regulation, emphasizing the lack of outside control and voluntary actions taken by platforms with minimal external intervention $[5,9,10,13]$.

At the other end of the spectrum is the regulation that emphasizes the role of governments in moderating content on platforms. It is known as direct regulation, external governance, statutory regulation, and comprehensive government regulation $[5,9,10,13]$. In this model, governments directly regulate platforms via laws and legislation. This model, however, can also be repressive, limiting free speech, as well as being too complex $[11,14]$. These debates reflected the difficulty of regulating false information $[15,16]$.

In the middle of the spectrum is the regulation that partners platforms and governments together, named co-governance, co-regulation, and limited government regulation $[5,9,10,13]$. An independent 3rd party regulator is always incorporated in this model and acts as a neutral regulating agency $[9,13]$. These actors are not always mutually agreeable. Governments sometimes threaten platforms with stricter regulation to motivate them to regulate themselves $[11,16]$.

A complementary model is the audience-centered approach to managing problematic information. It focuses on empowering audiences to discern for themselves [5], and it is used in combination with one of the other regulation models to increase their effectiveness or reduce the need for overzealous regulation [17]. All stakeholders-governments, platforms, and users - must be involved in regulation and contributing to the solution for it to be effective [18]. In a word, these models provide us an analytical foundation to understand the regulatory strategies by examining the relations among different stakeholders.

Existing discussion of these models falls into two groups. One is analyzing national policies and laws by different models $[10,13]$. The other one is categorizing countries into different models based on these predominant regulatory practices; for example, EU countries are under the co-regulation model in general with slight differences among countries, while China is under the direct regulation model [5]. Our analysis combines these two approaches to examine the changes in regulation practices in different countries during the pandemic and identify their differences.

\section{Methodology and Research Design}

Comparative policy analysis is the systematic study and comparison of public policies and policymaking in different jurisdictions to understand better the factors and processes that underpin similarities and differences in policy choices [19]. In this study, using a qualitative, comparative case study method, we selected five diverse cases and examined each government's policies regarding false information in the global pandemic context, including legislative acts, executive decrees, and administrative actions. We adopted the diverse case selection method [20], based on geographical location, government form, and democracy index [21] (see Table 1), for the purpose of identifying and comparing the similarities and differences among a variety of regulation models and the changes or stability of information policies before and during the pandemic. The five cases selected for this study also rank high in the number of internet users in their respective continents.

Table 1: Case Selection

\begin{tabular}{|l|l|l|l|}
\hline Country & Location & Government Form & $\begin{array}{l}\text { Democracy } \\
\text { Index Rank } \\
\text { and Type }\end{array}$ \\
\hline Argentina & $\begin{array}{l}\text { South } \\
\text { America }\end{array}$ & $\begin{array}{l}\text { Federal presidential } \\
\text { constitutional republic }\end{array}$ & $\begin{array}{l}48, \text { Flawed } \\
\text { democracy }\end{array}$ \\
\hline China & Asia & $\begin{array}{l}\text { Unitary Marxist- } \\
\text { Leninist one-party } \\
\text { socialist republic }\end{array}$ & $\begin{array}{l}151, \\
\text { Authoritarian }\end{array}$ \\
\hline France & Europe & $\begin{array}{l}\text { Unitary semi- } \\
\text { presidential } \\
\text { constitutional republic, } \\
\text { part of a Confederation } \\
\text { (EU) }\end{array}$ & $\begin{array}{l}\text { 24, Flawed } \\
\text { democracy }\end{array}$ \\
\hline U.K. & Europe & $\begin{array}{l}\text { Unitary parliamentary } \\
\text { constitutional } \\
\text { monarchy }\end{array}$ & $\begin{array}{l}\text { 16, Full } \\
\text { democracy }\end{array}$ \\
\hline U.S. & $\begin{array}{l}\text { North } \\
\text { America }\end{array}$ & $\begin{array}{l}\text { Federal presidential } \\
\text { constitutional republic }\end{array}$ & $\begin{array}{l}25, \text { Full } \\
\text { democracy }\end{array}$ \\
\hline
\end{tabular}

The study started with rigorous data collection, relying primarily on government websites. A combination of direct browsing and keyword searching strategies was used to collect any information related to "fake news," "rumors," "misinformation," "disinformation," and "conspiracy theories" on the national government websites and their major ministries, departments, branches, and offices. We also searched for relevant news on Google News and major news agencies in different countries using a combination of the above-mentioned keywords and "government," "policy," "legislation," "rules," and "orders." The data collection was conducted between May 2020 and April 2021, using the official language in each country, namely, Spanish, Chinese, French, and English.

The case analysis is loosely based on the regulation models drawn from the literature review, following the actor analysis method [22]. As many authors cited above, we look into two main actors, government and social media platforms with an emphasis on government policies, but other actors, such as content creators and norm guardians [23], are also included in the analysis. The social media 
platforms discussed in this paper are those popular platforms in the specific country contexts.

\section{Findings}

\subsection{Argentina}

Before the COVID-19 pandemic, Argentina's efforts against fake news focused on political and election misinformation, following a co-regulation approach. During its 2019 presidential election, fake news became a national concern [24]; as a result, two major collaborative efforts were initiated to combat false information. One effort was a collaboration under the lead of government authorities, namely, Cámara Nacional Electoral (CNE). Political parties, press associations, and digital platforms signed an agreement on Digital Ethics with CNE to protect the accuracy of electoral information [25]. In particular, Facebook cooperated with CNE closely and monitored suspicious activities during the presidential election [26]. Another effort was led by the Chequeado project, a nonpartisan and nonprofit fact-checking initiative focused on public access to information [27]. More than 100 media and technology companies and nongovernmental organizations formed a consortium called REVERSO and acted as an independent factchecker of electoral information [28].

The government of Argentina took a more direct regulation strategy during the pandemic, when false information was disseminated expansively through social media platforms. It was reported that the political divide in Argentina was deepened during the pandemic quarantine and the already existing economic crisis [29]. Rumors about government measures against the coronavirus, such as claims that the government stopped issuing passports "to prevent Argentines from leaving," were widespread [29].

On April 8, 2020, the National Security Ministry announced that the security forces would carry out "cyber-patrols" of social network content in order to detect crimes in relation to COVID-19, such as distribution of counterfeit drugs and to "ensure compliance with the quarantine norms" [30]. By April 20 , at least twelve criminal cases had been opened for "public intimidation," a crime punishable by up to six years in prison, under Argentina's zero-tolerance policy on the spread of false information and possibly as a result of the cyber patrol actions [30].

The government official claimed that cyber patrol was a legitimate tool to maintain the safety of the population and to prevent crime and envisioned it to be "part of the guidelines of the inter-American human rights system" [31]. However, such actions raised human rights concerns and criticisms against the administration for free speech, privacy, censorship, and power concentration. Various social organizations (norm guardians), including Amnesty International, expressed concerns over these direct government interventions and policing actions, accusing the government of using the pandemic as "an excuse to exercise massive, indiscriminate surveillance" over journalists and the citizens [32]. Yet these norm guardians' voices proved not to be very strong, and the government's role continued to grow.

In Argentina, the regulation of false information appears to transform from a pre-COVID co-regulation model to the during-COVID direct regulation model, where government holds tighter control and criminalizes false information distribution.

\subsection{China}

Before the pandemic, China had already established a sophisticated and comprehensive mechanism for internet control under direct regulation of the government [33] with a focus on cyberspace security, socialist spiritual civilization, and social stability. Fighting "fake news," always referred to as "rumors" in China, has been a crucial regulatory action. The regulatory tactics have included creating government agencies as a regulator, enacting laws and policies for regulating information creators and providers, criminalizing false information, and building centralized channels for fact-checking, official information spreading and rumor-reporting.

China started to set up its direct regulation mechanism in the early 2000s, marked by the Measures on Internet Information Services in 2000 to prohibit internet information services providers from producing or spreading rumors that disrupt social order or undermine social stability [34]. The control of false information became stricter in 2015 when China added "fabricating and disseminating false information that seriously disturbs public order" as a crime to its Criminal Law [35] and publicly deployed cyber police to patrol the internet for illegal and harmful information [36].

Corresponding to the direct regulation, the central government assigned a centralized Internet regulator - the Cyberspace Administration of China (CAC) - to coordinate and supervise online content regulation. In 2014, CAC incorporated the Illegal and Unhealthy Information Report Center to enhance its role in false-information reporting and online rumor monitoring [37]. CAC is also in charge of factchecking and becomes the authority of verifying the truth of information. The central CAC and its local branches collaborate with state-owned media, government agencies, and experts in different domains. They collectively launched a "Joint Rumor 
Rebuttal Platform" in 2018 as an official online channel to publish verified information.

Social media platforms, as information service providers, are also under CAC's direct regulation before the pandemic. CAC oversees the anti-rumor activities of these sites by tracing reported instances of false information on the major platforms. Frequently reported platforms ones are subject to punishments and penalties, including summoning, warning, administrative penalty, shutdown, etc. Under this pressure, these platforms have complied with the government's initiatives, such as "cleaning-up cyberspace" and "joint advocacy of self-regulation" under the government's direct orders and administration [38]. Large platforms also began to develop their own anti-rumor programs in 2015.

These sophisticated regulatory tactics have been rapidly enacted to fight against false information related to COVID-19 in a controversial way. China's direct regulation mechanism was criticized and challenged widely at the beginning of the pandemic for inhibiting the dissemination of factual information related to the novel coronavirus. In early January 2020 before the official announcement of the pandemic, eight individuals were accused of disturbing social order by creating false information which was later verified as truthful coronavirus information. The government responded to this irony by tightening its direct control over epidemic-related information and enhancing online censorship for maintaining stability.

In February 2020, CAC stressed the control of internet and online media by punishing rumor creators and releasing authoritative information. It developed a new module called "COVID-19 epidemic prevention and control and rumor debunking zone" on the antirumor platform [39]. A few mobile-based apps were removed from app stores and several social media platforms were summoned or temporary shut down for publishing illegal or harmful information related to COVID-19. On February $6^{\text {th }}$, judicial departments issued the "Opinions on Punishing Criminal and Illegal Activities that Hinder the Prevention and Control of Novel Coronavirus Pneumonia," which particularly emphasizes the battle against COVID-19 related rumors [40].

Social media platforms which have been incorporated into China's regulatory system also actively engaged in this battle by detecting and preventing rumors related to the pandemic. Many platforms rapidly responded to the crisis by expending anti-rumor programs with COVID-19 specific modules. Meanwhile, they blocked a broad scope of content, including not only speculative information, but also criticism of government, references to whistleblowers, and references to the Chinese government's efforts on handling the outbreak that had been reported on state media [41]. On February $7^{\text {th }}$ when the COVID-19 whistleblower, Dr. Li Wenliang, died, millions of users left messages to honor him on Sina Weibo and other social media. These posts, however, were periodically deleted.

The citizens are also similarly restricted. Hundreds of individuals were punished for spreading "pandemic related rumors" in the first quarter of 2020 [42]. Those "rumormongers" included not only entities that spread misleading information but also individuals who shared alternative information sources different from the official ones [43].

Chinese government has enhanced its direct regulation of online information during the pandemic and the social media platforms complied. Although actors from various sectors are involved in the collaborative anti-misinformation efforts, they are largely under the state's control. Compared to other countries, China's foci are monitoring and debunking rumors more than promoting media literacy.

\subsection{France}

As part of the EU, France's information policies cannot be completely separated from the EU's policies. Additionally, the French policies on false information directly impacted the EU policies [44], so this section also reports findings regarding the EU.

In the pre-COVID years, France's battle against false information was focused on election misinformation [45], and the government had direct regulations over fake news and political advertising [44]. French law had prohibited the "publication, dissemination or reproduction ... of fake news, [and] items that were made-up, falsified, or untruthfully attributed to third parties" since 1881 [46]. The law also limits paid political advertising.

In November 2018, France passed one of the earliest "fake news" laws in reaction to internet-based and social-media-based dissemination of disinformation [47]. This law enables judges to halt the dissemination of fake news during electoral campaigns, and enacts an innovative provision, asking social media platforms to carry the "duty of cooperation" and establish a "tool for users to flag disinformation" [47]. The specific duties of cooperation includes increasing algorithm transparency, promoting content of mainstream press agencies, removing fake accounts, disclosing sponsored content, and developing media literacy initiatives [47]. It also authorizes France's broadcasting regulator, the Higher Audiovisual Council (CSA), to oversee the cooperative measures taken by platforms, and it asks the platforms to designate staff members to facilitate dialogue with public authorities [47]. Facebook later stated that its 
measures to increase transparency in political advertising were "directly inspired by French regulation" [48].

France's approach can be considered as an example of "direct regulation" [5] or "statutory regulation" [9]. In contrast, the EU's Social Media Code of Practice on Disinformation represents the coregulation model [5] or "audited self-regulation" [9]. It focuses on the voluntary nature of the collaboration between governments and platforms, aiming at building "a framework for a structured dialogue ... to ensure greater transparency" [49]. Various platforms changed their content policies as responses to the Code of Practice. The EU also funded a joint EU-wide network for fact-checkers and set up an EU-wide rapid alert system for disinformation in 2019 [50].

During the COVID-19 pandemic, the EU, in addition to strengthening their current antimisinformation strategies and partnership, made more plans to battle COVID-19 false content, including establishing "an agile monitoring and reporting programme" in collaboration with more platforms [51]. More notable in the policy arena is European Parliament members' calls for more regulations on social media [52]. In response, the European Commission presented in late 2020 a new legislative initiative, the Digital Services Act (DSA), which proposes to establish standards and regulations for big technology companies regarding user data and the spread of disinformation online [53]. This initiative signifies the EU's move towards a stricter and more direct regulation model.

Our data does not show a prominent change of French policies regarding false information during the pandemic. Compared to other countries in this study, however, France's battle against false information was unique in that its public discourse centers on the freedom of press. In particular, the norm guardians (especially the traditional news/press agencies) have played a unique role in fighting false information while maintaining freedom of expression and media.

At the beginning of the pandemic, the French Minister of Culture stated France must combat fake news by providing access to independent sources of information [54]. The French Senate later commended four French media stations for their fight against fake news, stating that these stations had been essential sources of reliable information during a time of rumors and disinformation [55]. Furthermore, in response to the concerns over freedom of speech, France, together with a few other countries, issued a "Joint Statement on Safety of Journalists and Access to Information during the COVID-19 Crisis", which states that "free and independent media has an important role in pushing back against disinformation" and states or governments should not impede their work [56].
A more illustrative case may be the short-lived government-run website that was designed to combat coronavirus fake news by providing verified news. In May 2020 the French government launched the Désinfox website, selecting and publishing reliable articles to distribute. This effort was met with outrage by many journalists, media sites, and organizations, who called it an infringement on freedom of the press since the government was cherry-picking information [5]. The site was taken down a week later.

Although France's false-information regulation falls into the direct regulation categories, it shows distinct characteristics from other countries in this category (e.g., China). Moreover, different from many other countries, France's false-information policy has been relatively stable during the pandemic.

\subsection{The UK}

Like many other European countries, the UK government was mainly concerned over potential threats to national security and democracy caused by false information, particularly from foreign actors, before the pandemic [58]. These concerns drove the government to introduce collaborative initiatives for countering false information online and to discuss potential legislative actions.

In these initiatives, the UK government's strategy was to ensure high visibility of government information and raise public awareness about false information, rather than focus on rebutting false information. Several governmental departments and statutory bodies were tasked with investigating the impact of fake news and confirming factual information in 2018 [59]. The intelligence services under the Fusion Doctrine were responsible for identifying social media platforms distributing false information. The Cabinet Office launched the Rapid Response Unit (RRU) to monitor false information and reclaim a fact-based public debate. The RRU focused on providing highly visible public information and ensuring impactful government communication, particularly in times of crisis. In addition, the responsibility of the National Security Communications Team (NSCT) was expanded to tackle communications elements of threats to national security, including disinformation [58]. The NSCT also implemented media literacy campaigns to help the public better discern the reliability of online information [60]. Later, in 2019, the Office of Communications (Ofcom), the regulator of the communications services, also engaged in media literacy research and policy work by establishing a media advisory panel and forming a network of expert representatives from across the industry, the third sector, and academia. 
Meanwhile, the UK government was also in the process of considering legislative actions. In 2017, the Department for Digital, Culture, Media \& Sport (DCMS) initiated an 18-months inquiry on disinformation to understand the features of inaccurate information and evaluate its impact on both democracy and the individual [61]. Based on recommendations in the report resulting from this inquiry, DCMS and the Home Office issued the Online Harms White Paper in April 2019 with plans to tackle the issues of online harms, including disinformation. This white paper recommends the government to set "a new framework for ensuring disinformation is tackled effectively, while respecting freedom of expression and promoting innovation" [62].

As the threat of an infodemic increases during pandemic, the UK government has intensified their efforts by pushing the legislation process to regulate the platforms, enhancing media literacy, and increasing the visibility of accurate data.

The DCMS Select Committee published a COVID-19 "infodemic" report and urged the government to act swiftly to regulate platforms and false information. In February 2020 the government announced its intent to appoint Ofcom as the independent online harms regulator to implement and enforce the new regulatory framework [63]. During the pandemic, Ofcom provided information about factchecking and debunking sites and tools. It collected a set of resources to help cut through the confusion and provide people with the tools to navigate news and information about the coronavirus [64]. In December 2020, the DCMS and the Home Office published the Full Government Response to the Online Harms White Paper consultation and claimed to enact the online harms regulatory framework through legislation. The proposal would hand Ofcom the power to identify "lawful but harmful" content and to fine and block the sites of social media giants [62].

The UK government also adopted other actions, such as launching a GOV.UK Coronavirus Information service on WhatsApp to provide official and timely information and advice about COVID-19 $[65,66]$. In addition, the UK government enhanced the detection of pandemic related false information and public education by collaborating with international organizations and academia. The RRU assigned dedicated specialists to identify instances of false information on social media, and then coordinated with the platforms to either remove or rebuttal them. The government also worked with WHO for promoting a global campaign of "Stop The Spread" to raise awareness about the risks of false information around COVID-19 [67], and invested $£ 29$ millions of government funding to support six research centers across the UK to address challenges around online safety and privacy, including the spread of disinformation [68].

In summary, before the pandemic, the antimisinformation practices in the UK were scattered without any specific laws to prohibit the publication of online false information. The pandemic has accelerated the formation of a co-regulation model under the legislation framework in the UK.

\subsection{The US}

Before the pandemic, the US had more foci than any other country in combatting false information, including "[p]olitical ads, foreign disinformation, general misinformation, media literacy and deepfake videos" [45]. What they lacked, however, was a topdown, national policy response or large-scale collaborative initiatives.

During the 2016 presidential campaign, many incidents of hacking, social media account manipulation, and foreign interference were reported and investigated [69]. The US Senate announced a bill in October 2017 to regulate political ads on the internet, called the Honest Ads Act, aiming to bring similar rules used for traditional media to social media platforms [70]. The effort to regulate platforms regarding political advertisements was unsuccessful, and social media platforms remained largely selfregulated. Facebook, Twitter, and Google admitted to the Senate that Russia manipulated their platforms but were confident in their own measures to monitor fake accounts and ad buyers [71].

Faced with the spreading of fake news, some state governments introduced bills trying to monitor false information on social media, but these failed too [72]. The only successful policy action was the enactment of several state laws that mandate improving media literacy through civic or public education [45].

During the pandemic, the concerns and debates over false information intensified greatly, leading to increased action from the US government. Many government departments and agencies, including FEMA, the CDC, and the CISA, have sections of their websites dedicated to rumor control, answering frequently asked questions, dispelling myths, and pointing the public to scientific, accurate information sources [73-75]. Congress has introduced a bill known as the "COVID-19 Misinformation and Disinformation Task Force Act of 2020," which recognizes the importance of a "coordinating understanding" as well as a "whole-of-government approach" in the US's fight against the spread of COVID-19 related false information [76]. It also outlines the importance of improving media literacy. In addition, Congress has passed a resolution "condemning anti-Asian discrimination relating to 
coronavirus" in an attempt to address a new side of COVID-19 disinformation [77].

The pandemic also prompted increased conversation between the US government and platforms. One Congressman wrote to the CEOs of major platforms, praising them for the actions they have taken, but urging them to increase their efforts to combat online false information [78]. Such conversation, however, is fraught with tension, as exemplified by the rug of ward between the thenpresident, Trump, and the social media platforms. Trump passed an Executive Order on "Preventing Online Censorship," which addresses the "selective censorship" of the platforms and attempts to hold them liable for their content [79]. Platforms have pushed back, even going so far as to remove posts made by Trump and freezing his account for content in violation of the companies' COVID-19 misinformation policies [80].

The concerns over the role of social media in spreading false information were also heightened among the public during the pandemic. For example, public organizations and policy institutes such as the Center for American Progress pushed social media platforms to "fundamentally rethink their products to reduce the health risks posed by disinformation and misinformation about the coronavirus crisis" [81]. The public may be calling for more effective information policies, but the government has made little progress in the realm of formal regulation.

Another arena of the US's false-information battle was foreign affairs. The US Department of State and Trump made many remarks regarding China and COVID-19, blaming China for false information and non-transparency. The Senate also passed a resolution blaming China for intentionally spreading misinformation to downplay the risks of COVID-19 and internal censorship of doctors and journalists [82].

Multiple actors with different values and interests play their roles in the information policy arena of the US. The foci of fighting false information shifted before and during the pandemic, but the overall regulation model shows little change-self regulation is still the dominant model.

\section{Discussions}

Triggered by the unexpected universal threat, national governments actively responded to false information by regulating online content and social media platforms using both legislative actions and collaborative initiatives. The comparative case analysis demonstrates that many national governments tried to enhance the role of state in the battle against the mis-infodemic during the COVID-19 crisis, no matter what political regime they have or what regulation models they adopted before the pandemic. However, their attempts were not always successfulfor example, the US policymakers are still debating, and France's effort to publish select truthful information has failed. The existing social norms, values, and power dynamics among policy actors are all possible explanations for these policy outcomes.

The case analysis also shows that the regulation frameworks of false information are emerging and evolving during the pandemic in each country differently. In Argentina, the regulation is transforming from a co-regulation to a more direct regulation model, where the government holds tighter control and imposes more interventions, such as cyber patrol. In the UK, direct interventions from the UK government are limited, but the UK government seems to have started shifting from a loose collaboration to a more formal co-regulation model with an appointed independent regulator under the newly proposed legislative framework. The Chinese government enhanced its existing direct regulation framework during the pandemic and tightened the control of platforms by revising and strengthening its laws, policies, and enforcement. The US and France do not show a clear change in their regulation models. However, the US's information policy arena has more negotiations among relevant actors than ever before, which is likely to shape future policymaking. The practice in France, on the other hand, shows a unique path. Although having adopted a direct regulation model, the French government encourages traditional media to provide independent sources of information and protect the freedom of speech. This emphasis on empowering the audience makes France's direct regulation distinct from China's and Argentina's.

This study draws from the existing literature on false-information regulation, especially the four regulation models - self regulation, co-regulation, direct regulation, and audience-centered model $[5,9,10,13]$. Our findings imply the limitations of using these models as analytical frameworks. As some scholars have mentioned in the literature, the models may not be mutually exclusive in practice [5]. Indeed, our case study reveals a trend of combining different regulation strategies in practice that blur the boundaries between each model. We found a variety of policy actions that may not fit into any of the existing models. For example, collaboration, a key feature of the co-regulation model, also appears to be a common practice in other models, even in countries that adopted the direct regulation model. For instance, the Chinese government collaborates with social media platforms to trace rumors and works with traditional media and academia for factchecking. France is considered as the typical example of direct regulation, but the nature of the regulation can 
be considered as co-regulation because the French government uses law to require social media platforms' collaboration rather than imposing specific rules on content. From this perspective, the so-called models and predefined static categories may overlap too much to be useful for meaningful, theoretical analysis. Re-evaluating the characteristics of different regulatory practices and extracting new models might be necessary for both researchers and practitioners as analytical tools or practical guidance.

Our study selected five countries as a showcase of diverse false-information regulation practices and used the existing typology of regulation models as a loose analytical framework to examine the actions of different stakeholders and their interactions, with a focus on governments' policies. Because of the limited scope of data collection and the small number of cases, findings are not generalizable at the current stage. However, this study sheds light on future research. First, future research can use a relational perspective to unpack how different actors engage in the regulation. Examining the relations between the state, platforms, and the public will be helpful for us to understand the momentum of the regulation formation and change. Second, our analysis reveals the influence of social media platforms and norm guardians (including traditional press, journalists, and public interest groups), whose reactions and initiatives also shape the regulating process. Last but not least, expanded studies with more cases will create a more comprehensive and theoretical understanding of falseinformation regulations around the globe.

\section{Conclusion}

The pandemic crisis triggered changes of regulations in different countries. The state and the various social media platforms, in most cases, are still the dominant actors in false-information policymaking, but other actors are increasingly involved. This study looks beyond the western world and includes cases in different regions of the world. The findings provide empirical evidence on falseinformation policies and sheds light on a more nuanced understanding of regulation. Our future research will include in-depth analysis of the roles of more actors from a relational perspective and the development of a more useful analytical framework.

\section{References}

[1] UN News, "Hatred Going Viral in 'Dangerous Epidemic of Misinformation' during COVID-19 Pandemic," April 2020. https://news.un.org/en/story/2020/04/1061682.
[2] Wardle, C., "The Need for Smarter Definitions and Practical, Timely Empirical Research on Information Disorder." Digital Journalism 6, no. 8 (2018): 951-963.

[3] Egelhofer, J. L., and S. Lecheler, "Fake News as a TwoDimensional Phenomenon: A Framework and Research Agenda." Annals of the International Communication Association 43, no. 2 (2019): 97-116.

[4] Cavaliere, P., "From Journalistic Ethics to FactChecking Practices: Defining the Standards of Content Governance in the Fight against Disinformation." Journal of Media Law 12, no. 2 (July 2020): 133-65.

[5] Durach, F., A. Bargaoanu, and C. Nastasiu, "Tackling Disinformation: EU Regulation of the Digital Space." Romanian Journal of European Affairs 20, no.1 (2020): 520 .

[6] Hartley, K., and M. K. Vu, "Fighting Fake News in the COVID-19 Era: Policy Insights from an Equilibrium Model." Policy Sciences 53, no.4(December 2020):735-58. [7] Rodrigues, U. M., and J. Xu, "Regulation of COVID-19 Fake News Infodemic in China and India." Media International Australia 177, no. 1 (2020): 125-31. [8] Gillespie, T., Custodians of the Internet: Platforms, Content Moderation, and the Hidden Decisions That Shape Social Media. Yale University Press, 2018.

[9] Marsden, C., T. Meyer, and I. Brown, "Platform Values and Democratic Elections: How Can the Law Regulate Digital Disinformation?" Computer Law \& Security Review 36 (2020): 18.

[10] Rochefort, A., "Regulating Social Media Platforms: A Comparative Policy Analysis." Communication Law and Policy 25, no. 2 (2020): 225-60.

[11] Tenove, C., "Protecting Democracy from Disinformation: Normative Threats and Policy Responses." The International Journal of Press/Politics 25, no. 3 (2020): 517-37.

[12] Van Dijck, J., "Seeing the Forest for the Trees: Visualizing Platformization and Its Governance." New Media \& Society, (July 2020): 1-19.

[13] Gorwa, R., "What Is Platform Governance?" Information, Communication \& Society 22, no.6(2019):19. [14] Tambini, D., "Fake News: Public Policy Responses." London School of Economics and Political Science, 2017. [15] Baade, B., "Fake News and International Law." European Journal of International Law 29, no. 4 (December 2018): 1357-76.

[16] Pielemeier, J., "Disentangling Disinformation: What Makes Regulating Disinformation so Difficult?" Utah Law Review, no. 4 (August 2020): 917-40.

[17] Medeiros, B., and P. Singh, "Addressing Misinformation on Whatsapp in India through Intermediary Liability Policy, Platform Design Modification, and Media Literacy.” Journal of Information Policy, 10(2020):276-98. [18] Helberger, N., J. Pierson, and T. Poell, "Governing Online Platforms: From Contested to Cooperative Responsibility." The Information Society 34, no. 1 (January 2018): 1-14.

[19] Schmitt, S., "Comparative Approaches to the Study of Public Policy-Making," in Routledge Handbook of Public Policy, ed. Eduardo Araral et al. (London, UK: Taylor \& Francis Group, 2012). 
[20] Rohlfing, I., Case Studies and Causal Inference: An Integrative Framework. Houndmills, UK: Palgrave Macmillan, 2012.

[21] The Economist Intelligence Unit, "Democracy Index 2020: In Sickness and in Health?" Accessed August 06, 2021, https://pages.eiu.com/rs/753-RIQ-

438/images/democracy-index-2020.pdf

[22] Hermans, L., and W. Thissen, "Actor Analysis Methods and Their Use for Public Policy Analysts," European Journal of Operational Research, 196 (July 2009): 808-18.

[23] Baron, S., and R. Crootof, "Fighting Fake News Workshop Report" (The Information Society Project and the Floyd Abrams Institute for Freedom of Expression, October 2017),

https://law.yale.edu/sites/default/files/area/center/isp/docu ments/fighting_fake_news_-_workshop_report.pdf. [24] Rodriguez-Ferrand, G., "Government Responses to Disinformation on Social Media Platforms: Argentina," September 2019, https://www.loc.gov/law/help/socialmedia-disinformation/argentina.php.

[25] “Compromiso Ético Digital," accessed June 2, 2021, https://perma.cc/J9GZ-MCL6.

[26] "Memorándum de Cooperación," accessed June 2, 2021, https://perma.cc/7FBX-KKE9.

[27] "Acerca de Chequeado - Chequeado," accessed June 2, 2021, https://perma.cc/PS6S-3ZYL.

[28] "Reverso," accessed June 2, 2021, https://perma.cc/93HS-DWRJ.

[29] Buenos Aires Times, "Coronavirus Quarantine Revives Argentina Famous 'Grieta,'” accessed October 15, 2020, https://www.batimes.com.ar/news/argentina/corona virus-quarantine-revives-argentina-famous-grieta.phtml. [30] Buenos Aires Times, "Criminal Cases Opened for Spreading Disinformation about Covid-19," accessed September 17, 2020, https://www.batimes.com.ar/news/ argentina/open-criminal-cases-for-disinformation-aboutcovid-19-in-argentina.phtml.

[31] Argentina.gob.ar, "Ciberpatrullaje: reunión del Defensor del Pueblo porteño y la Ministra de Seguridad de la Nación," April 15, 2020, https://www.argentina.gob.ar/noticias/ciberpatrullajereunion-del-defensor-del-pueblo-porteno-y-la-ministra-deseguridad-de-la.

[32] Belski, M., "Letter to Minister of Security from Amnesty International Argentina," April 21, 2020, https://amnistia.org.ar/wp-content/uploads/delightfuldownloads/2020/04/DOC-_AIAR-_PJI-_21042020.pdf. [33] Yang, G.,"A Chinese Internet? History, Practice, and Globalization," Chinese Journal of Communication 5, no. 1 (March 2012): 49-54.

[34] Congressional-Executive Commission on China, "Measures for the Administration of Internet Information Services," 2000, https://www.cecc.gov/resources/legalprovisions/measures-for-the-administration-of-internetinformation-services-cecc.

[35] Amendment (IX) to the Criminal Law of the People's Republic of China, 2015.

[36] Magnier, M., "China's Internet Police Step Out of the Shadows," The Wall Street Journal, June 1, 2015, https://www.wsj.com/articles/BL-CJB-26989.
[37] "An Introduction to China Internet Illegal and Unhealthy Information Complaint Center," 2014, https://web.archive.org/web/20180801190640/http://www. 12377.cn/txt/2014-09/02/content_7198763.htm.

[38] Sina tech, "Six Internet Companies Initiated Joint Advocacy of 'Purifying Internet,"' accessed June 5, 2021, http://news.sina.com.cn/m/wl/2015-10-30/docifxkhcfk7451466.shtml.

[39] Cyberspace Administration of China, "Epidemic Prevention and Rumour-Debunking Page," accessed June 7, 2021, https:/www.piyao.org.cn/2020yqpy/.

[40] "The Opinions on Punishing Criminal and Illegal Activities That Hinder the Prevention and Control of Novel Coronavirus Pneumonia," accessed June 5, 2021, http://lawinfochina.com/display.aspx?id=32144\&lib=law. [41] Citizen Lab, "Censored Contagion: How Information on the Coronavirus Is Managed on Chinese Social Media," March 3, 2020, https://citizenlab.ca/2020/03/censoredcontagion-how-information-on-the-coronavirus-ismanaged-on-chinese-social-media/.

[42] Chinese Human Rights Defenders, "China: Protect Human Rights While Combatting Coronavirus Outbreak" January 31, 2020, https:/www.nchrd.org/2020/01/chinaprotect-human-rights-while-combatting-coronavirusoutbreak/.

[43] Chinese Human Rights Defenders, "List of Penalized Chinese Netizens for Online Speech about COVID-19," March 26, 2020.

[44] Boring, N., "Government Responses to Disinformation on Social Media Platforms," September 2019, https://www.loc.gov/law/help/social-mediadisinformation/france.php\#_ftn29.

[45] Funke, D., and D. Flamini, "A Guide to AntiMisinformation Actions around the World," accessed June 3, 2021, https://www.poynter.org/ifcn/anti-misinformationactions/.

[46] Legifrance, "Loi Du 29 Juillet 1881 Sur La Liberté de La Presse," accessed June 3, 2021,

https://perma.cc/WV8K-YNF9.

[47] Legifrance, "LOI N²018-1202 Du 22 Décembre

2018 Relative à La Lutte Contre La Manipulation de

l'information," accessed June 3, 2021,

https://perma.cc/QH5N-25MC.

[48] LeLoup, D., and A. Piquard, "Les Pubs Politiques Sur Facebook En Europe Seront Accompagnées Du Message « Payé Par... »," accessed June 3, 2021,

https://perma.cc/BL7A-KKFF.

[49] European Commission, "Disinformation: EU Assesses the Code of Practice," accessed September 23, 2020, https://ec.europa.eu/commission/presscorner/detail/en/ip_2 0 1568.

[50] European External Action Service, "Questions and Answers about the East StratCom Task Force," accessed June 4, 2021, https://eeas.europa.eu/headquarters/ headquarters-homepage/2116/questions-and-answersabout-east-stratcom-task-force_en.

[51] European Commission, "Tackling Covid-19 Disinformation," accessed November 5, 2020, https://ec. europa.eu/info/sites/info/files/communication-tacklingcovid-19-disinformation-getting-facts-right_en.pdf. [52] European Parliament, "Digital: EU Must Set the Standards for Regulating Online Platforms, Say MEPs" 
October 20, 2020,

https://www.europarl.europa.eu/news/en/pressroom/20201016IPR89543/digital-eu-must-set-thestandards-for-regulating-online-platforms-say-meps. [53] European Commission, "The Digital Services Act Package" accessed May 5, 2021, https://digital-strate gy.ec.europa.eu/en/policies/digital-services-act-package. [54] Ministère de la Culture, "Discours de Franck Riester, ministre de la Culture," accessed September 19, 2020, https://www.culture.gouv.fr/Presse/Discours/Discours-deFranck-Riester-ministre-de-la-Culture-prononce-a-1occasion-de-la-reunion-des-ministres-de-la-CultureUNESCO-mercredi-22-avril-2020.

[55] "French Media Fighting Fake News," accessed October 29, 2020, http://www.senat.fr/fileadmin/Fichiers/ Images/commission/affaires_etrangeres/Coronavirus_suivi/ 4pages_communication_ecrite_audiovisuel_Final.pdf. [56] Ministère de l'Europe et des Affaires Étrangères, "Joint Statement on Safety of Journalists and Access to Information during the COVID-19 Crisis."

[57] LeMonde, “«L'Etat n'est pas l'arbitre de l'information »," May 3, 2020,

https://www.lemonde.fr/idees/article/2020/05/03/1-etat-nest-pas-1-arbitre-de-1-information_6038527_3232.html. [58] Feikert-Ahalt, C., "Government Responses to Disinformation on Social Media Platforms: United Kingdom," September 2019, https://www.loc.gov/law/help/social-mediadisinformation/uk.php.

[59] Tannam, E., "UK Government to Establish New Unit to Battle Onslaught of Fake News," January 24, 2018, https://www.siliconrepublic.com/enterprise/uk-fake-newsunit.

[60] "SHARE Checklist," accessed June 12, 2021, https://sharechecklist.gov.uk/.

[61] House of Commons, "Disinformation and 'Fake News': Final Report,” February 14, 2019,

https://publications.parliament.uk/pa/cm201719/cmselect/c mcumeds/1791/1791.pdf.

[62] Gov.uk, “Online Harms White Paper," accessed November 11, 2020,

https://www.gov.uk/government/consultations/onlineharms-white-paper/online-harms-white-paper.

[63] "Misinformation in the COVID-19 Infodemic:

Government Response to the Committee's Second Report" accessed June 9, 2021, https://publications.parliament. $\mathrm{uk} / \mathrm{pa} / \mathrm{cm} 5801 / \mathrm{cmselect} / \mathrm{cmcumeds} / 894 / 89402 . \mathrm{htm}$. [64] Ofcom, "Covid-19 News and Information: Consumption and Attitudes," May 25, 2021, https://www.ofcom.org.uk/research-and-data/tv-radio-andon-demand/news-media/coronavirus-news-consumptionattitudes-behaviour.

[65] Gov.uk, "Government Launches Coronavirus

Information Service on WhatsApp," accessed June 9, 2021, https://www.gov.uk/government/news/governmentlaunches-coronavirus-information-service-on-whatsapp. [66] Ofcom, "Combatting Covid-19 Misinformation," March 1, 2021, https://www.ofcom.org.uk/research-anddata/media-literacy-research/coronavirus-resources.

[67] WHO, "Countering Misinformation about COVID-19: A Joint Campaign with the Government of the United Kingdom," accessed June 12, 2021, https://www.who.int/news-room/featurestories/detail/countering-misinformation-about-covid-19. [68] Gov.uk, "£29 Million Government Funding to Boost Digital Revolution and Help Keep People Safe Online,” accessed June 12, 2021,

https://www.gov.uk/government/news/29-milliongovernment-funding-to-boost-digital-revolution-and-helpkeep-people-safe-online.

[69] CNN Editorial Research, "2016 Presidential Campaign Hacking Fast Facts,” accessed June 4, 2021, https://www.cnn.com/2016/12/26/us/2016-presidentialcampaign-hacking-fast-facts/index.html.

[70] Honest Ads Act, S.1989, 115 Congr. (2018)

[71] The Guardian, "Facebook, Google and Twitter Grilled by Congress over Russian Meddling" accessed June 4, 2021, https://www.theguardian.com/technology/live/2017/oct/31/ facebook-google-twitter-congress-russian-electionmeddling-live.

[72] CBS Sacramento, "Governor Brown Vetoes Fake News Bill, Calls It 'Not Necessary," September 27, 2018, https://sacramento.cbslocal.com/2018/09/27/californiafake-news-bill-veto/.

[73] CISA, "We're in this together. Disinformation stops with you," accessed June 10, 2021,

https://www.cisa.gov/sites/default/files/publications/SLTT COVIDToolkit_FINAL_508.pdf.

[74] CDC, "Buyer Beware: How to Avoid Scams \& Misinformation during COVID-19" Accessed September 12, 2020.https://blogs.cdc.gov/publichealthmatters/2020/06/be ware-scams/.

[75] FEMA, "Coronavirus Rumor Control," accessed September 10, 2020.

https://www.fema.gov/disasters/coronavirus/rumor-control. [76] COVID-19 Misinformation and Disinformation Task Force Act of 2020, S. 4499, 116 Congr. (2020).

[77] Brufke, J., "House passes resolution condemning antiAsian discrimination relating to coronavirus," September 17, 2020. https://thehill.com/homenews/house/516909house-passes-resolution-condemning-anti-asiandiscrimination-in-relation-to.

[78] Casiano, L., "Schiff demans Google, YouTube, Twitter alert users to coronavirus misinformation to prevent spread," April 30, 2020.

https://www.foxnews.com/politics/schiff-demands-googleyoutube-twitter-alert-users-viewing-spreading-coronavirusmisinformation.

[79] "Executive Order 13925 of May 28, 2020, Preventing Online Censorship," Federal Register 85, no. 106 (June 02, 2020): 34079.

[80] Manfredi, L., "Facebook removes Trump post over coronavirus misinformation rules; Twitter also clamps down," August 5, 2020.

https://www.foxnews.com/politics/facebook-twitterremoves-post-trump-coronavirus-misinformation.

[81] Simpson, E., and A. Conner, "Fighting Coronavirus Misinformation and Disinformation," accessed September 12, 2020, https://www.americanprogress.org/issues/ technology-policy/reports/2020/08/18/488714/fightingcoronavirus-misinformation-disinformation/.

[82] S.Res.553, 116 Congr. (2020):

https://www.congress.gov/bill/116th-congress/senateresolution/553. 